\title{
Representatividade feminina e relações de gênero em um livro de inglês aprovado pelo PNLD
}

\author{
Daniela Conegatti*
}

\section{Resumo}

Este artigo apresenta os dados da análise de um livro didático aprovado pelo PNLD de 2018, para o ensino de língua inglesa, no que tange questões de gênero e sexualidade. O referencial teórico compreendeu os estudos de gênero e sexualidade, com base em Louro (2000; 2004; 1997), Weeks (2000) e Butler (2004), e a metodologia, a análise de discurso com base em Foucault $(1989 ; 2005)$ e a desconstrução por meio da perspectiva Queer. O trabalho analítico evidenciou como o livro recorreu a lugares normativos de gênero e sexualidade para produzir conhecimento em língua inglesa.

Palavras-Chave: Gênero; Livro didático; Inglês.

\section{Female representativity and gender expectations in an english book approved by the PNLD}

\section{Abstract}

This paper presents the analysis of an English textbook approved by the PNLD of 2018, with regard to gender and sexuality issues. The theoretical framework included gender and sexuality studies, based on Louro (2000; 2004; 1997), Weeks (2000) and Butler (2004), and the methodology was composed by the theory of discourse based on Foucault $(1989 ; 2005)$ allied to the deconstruction through the Queer perspective. The analytical work shows how the book made use of normative misconceptions of gender and sexuality to produce knowledge regarding the English language.

Keywords: Gender; Textbook; English.

\footnotetext{
* https://orcid.org/0000-0002-1143-2277

http://lattes.cnpq.br/3103772424611465

UFRGS
} 


\section{Representatividad femenina y relaciones de géne- ro en un libro en inglés aprobado por PNLD}

\section{Resumen}

Esta investigación presenta los datos del análisis de un libro de texto aprobado por la PNLD de 2018, para la enseñanza del idioma inglés, en materia de género y sexualidad. El marco teórico incluyó estudios de género y sexualidad, basados en Louro (2000; 2004; 1997), Weeks (2000) y Butler (2004), y la metodología de análisis del discurso basada en Foucault (1989; 2005) y deconstrucción a través de la perspectiva Queer. El trabajo analítico concibió cómo el libro utilizó lugares normativos de género y sexualidad para producir conocimiento en el idioma inglés.

Palabras-clave: Género; Libro de texto; Inglés.

Em 2017, o Programa Nacional do Livro Didático lançava mais uma vez seu guia, cujo propósito é, para além de apresentar os livros escolhidos para a edição de 2018 do programa, indicar também aquilo que neles é preciso aprimorar. Uma das questões apontadas na maior parte dos livros da área de línguas, pelo menos, é o compromisso com questões de direitos humanos, cujo trabalho é assegurado não apenas pelos Parâmetros Curriculares Nacionais (BRASIL, 1997; 2002), mas também pelas Diretrizes Curriculares Nacionais (Idem, 2013).

A partir destas considerações, e na esteira de pesquisas que evidenciam a importância do estudo da produção de gênero e sexualidade nos livros didáticos (SILVA \& COUTINHO, 2016; OLIVEIRA, 2017), efetuou-se aqui a análise de um dos livros aprovados e constituintes do guia do PNLD para o ensino de Língua Estrangeira Moderna (LEM), mais especificamente, no que tange ao ensino da língua inglesa: o livro Way To Go. A seleção deste livro se deu para que, posteriormente, fosse empregada uma análise discursiva do seu conteúdo, com base em Michel Foucault (2005; 1989), e, também, visando a uma estratégia descritivo-analítica inspirada pela perspectiva Queer (LOURO, 2004), de forma a entender como são produzidos lugares de gênero e sexualidade no material analisado. A bibliografia referente à gênero e sexualidade foi com- 
posta por autoras como Guacira Louro (2000; 2004; 1997), Jeffrey Weeks (2000) e Judith Butler (2004).

Para além das pesquisas referenciadas que evocam a importância de que estudos com enfoque em temas transversais sejam realizados com/sobre materiais didáticos, ressalta-se que investigações como a realizada neste artigo contribuem para o aprimoramento de materiais didáticos futuros, ao lançarem luz sobre o potencial pedagógico de enunciados, imagens, discursos geralmente considerados secundários na confecção de um material didático, onde as atenções permanecem, via de regra, voltadas para o conteúdo programático a partir do currículo específico da disciplina (isto é, questões de ordem técnica que compõem a matéria de estudo, que a/o discente precisa dominar para progredir em sua formação).

Importante destacar que esta pesquisa compreende as análises de um livro aprovado pelo PNLD em 2017 e distribuído em 2018 em todo o território nacional. Como é possível que cada região escolha apenas um livro didático dentre um leque de possibilidades apresentadas e subsidiadas pelo PNLD, dados sobre o impacto deste livro específico não estão, até o momento, acessíveis.

Antes de adentrar as discussões teóricas e analíticas, ressalta-se que o presente artigo está estruturado da seguinte forma: primeiramente, fez-se uma breve discussão sobre o lugar de gênero e sexualidade no contexto do currículo escolar, com destaque para a relação entre os PCNs, os Temas Transversais, o PNLD e o livro didático; sequencialmente, a metodologia da análise de discurso foucaultiana e da perspectiva Queer foi apresentada; por fim, as análises do livro didático foram discutidas à luz das teorias. Um capítulo final dedicado às considerações finais também compõe este artigo.

\section{Gênero e sexualidade no currículo escolar}

$\mathrm{Na}$ presente pesquisa, parte-se de uma perspectiva que não resume o ser humano a sua constituição biológica. Os estudos de gênero e sexualidade socioculturais emergem como referência, na medida em que enfatizam o caráter histórico e construído do sexo, 
do gênero e da sexualidade (LOURO, 1997). E se, portanto, gênero, sexo e sexualidade são entendidos como construções socioculturais e linguísticas, seus efeitos também o são. Frente a este cenário, a Educação - inclusive a escolar - encontra a necessidade de posicionamento ético, de forma a desconstruir desigualdades profundas constituídas a partir do rechaço à diferença. Mais especificamente, de forma a trabalhar pela equidade de gênero e de sexualidade.

É neste sentido que a escola foi e é, também, produtora de pedagogias da sexualidade e do gênero, conceituadas por Louro (2000) como formas de disciplinamento dos corpos no que concerne àquelas categorias. Ou seja, a linguagem constitui gênero e sexualidade não apenas para além da escola, mas também dentro dela, de forma que ensina a discentes modos de ser, de viver, de se relacionar consigo ou com as(os) outras(os), disciplinando seus corpos e naturalizando certas concepções sociais em detrimento de outras. Algumas dessas configuram formas sutis, mas o que as torna efetivas é a continuidade, o reforço que as instituições (incluindo a escola) e a sociedade empregam sobre elas, que podem ser práticas, discursos, saberes, expectativas. Nesse sentido, o livro didático, enquanto artefato cultural constitutivo do ambiente escolar, emerge como produtor de pedagogias do gênero e da sexualidade. Torna-se, então, imperativo verificar como esse artefato pedagógico-cultural vem produzindo gênero e sexualidade.

Antes de abordar, contudo, a operação analítica sobre o livro, importa entender o lugar que pode ocupar o gênero e a sexualidade no livro didático, de acordo com a legislação e as normativas vigentes.

O PNLD é o programa responsável pela avaliação, seleção e posterior distribuição de livros didáticos para as escolas públicas de Educação Básica de todo o Brasil. A cada ano, um edital é lançado para a seleção de livros didáticos, que podem ser, a partir da avaliação de uma equipe técnica específica para cada matéria, aprovados ou reprovados. Juntamente com a publicação dos livros aprovados, o PNLD publica um guia, que visa a orientar a escola e a(o) docente na escolha do livro a ser utilizado, bem como a esclarecer as formas 
e critérios de avaliação dos livros. O guia divulga, também, quais aspectos ainda merecem mais atenção, isto é, precisam ser aprimorados para as próximas edições dos livros aprovados.

Assim sendo, configura documento importante, que além de servir de guia para as editoras de livros didáticos, compõe em seu texto o compromisso com os PCNs (BRASIL, 1997), os PCNs+, de 2002, que competem ao Ensino Médio, e com as Diretrizes Curriculares Nacionais para a Educação Básica (BRASIL, 2013). Estes três documentos reconhecem não apenas a dimensão biológica da sexualidade, mas a psíquica e sociocultural. Consequentemente, o texto do guia reforça o entendimento de que a sexualidade já está presente na escola, uma vez que as(os) discentes vivem em contato com o assunto por meio de outras fontes, seja a família, a mídia, as(os) amigas(os).

Segundo o guia, o Edital do PNLD de 2017 (para aprovação dos livros de 2018), em seu Anexo III, indica que os livros didáticos da área devem abordar questões como a imagem da mulher, além de reforçar seu protagonismo, combater problemas como sexismo e lgbtfobia, e buscar a superação de violências concernentes a estas populações, com destaque para a violência contra a mulher. (BRASIL, 2017, p.12).

Neste sentido, o próprio guia legitima a importância de tais assuntos perpassarem, de forma transversal, os livros didáticos. Em relação ao livro de Língua Estrangeira Moderna (LEM), ele apresenta alguns critérios específicos da área, que guiaram a seleção tanto dos livros de Inglês quanto dos livros de Espanhol. O compromisso com discussões acerca de questões socialmente relevantes, o favorecimento do "acesso à diversidade cultural, social, étnica, etária e de gênero" de modo a enfatizar sua contribuição linguística (BRASIL, 2017, p.21-22), são apenas alguns importantes de serem destacados. No que se refere aos critérios legais, éticos e democráticos, o guia indica a necessidade de a coleção não reforçar preconceitos "relativos às condições social, regional, étnico-racial e de gênero, à orientação sexual, à idade, à linguagem, à religião, à condição de deficiência, assim como 
a qualquer outra forma de discriminação ou de violação de direitos humanos" (BRASIL, 2017, p.23).

Estes critérios não apenas demonstram o compromisso do PNLD com diversos documentos da Educação que defendem os direitos humanos, mas servem de guia, aqui, para questões a serem observadas no livro didático analisado. Em certo sentido, talvez a análise de critérios que, teoricamente, já foram avaliados pelo próprio guia, possa parecer desnecessária. Contudo, os referenciais teóricos não são os mesmos, o que pode mudar substancialmente os resultados, e, para além disso, o documento atenta para uma questão importante, que é a de que nem todos os livros cumpriram satisfatoriamente os critérios, ao sugerir modificações para edições futuras (BRASIL, 2017).

Como efeito, a proposta que se estabelece neste artigo supera a questão de se há discussões acerca de gênero e sexualidade nos livros, justamente por entender que gênero e sexualidade perpassam a lógica estrutural de quaisquer âmbitos sociais. Nesse sentido, aqui busca-se entender de que forma essa discussão está presente no livro a ser analisado, de modo a priorizar o "como", com enfoque em uma abordagem mais descritivo-analítica, além de qualitativa. Os caminhos metodológicos específicos sobre a análise são expressos a seguir.

\section{Proposta: uma análise de discurso queer}

Para Foucault (1989), as verdades são criações sócio-históricoculturais e linguísticas, ou seja, são produtos de um dado contexto e de um dado tempo. Quando cita "as verdades", o autor refere-se às compreensões cuja sedimentação temporal naturaliza seu status, de modo a não provocar resistência em relação a seu conteúdo - adquirindo, assim, status de verdade. A teoria unissexual, proposta no século II d.C., por Galeno, que concebia o sexo dos corpos como apenas um, dependente do calor vital que levava o corpo com pênis à perfeição e o corpo com vulva a ser sua derivação imperfeita, (LAQUEUR, 2001), é um interessante exemplo de discurso que regeu as verdades biológicas de um determinado tempo. 
Assim, para Foucault (1989), é mais pertinente falar em regimes de verdade, em discursos que adquirem caráter de verdade. Sua noção de discurso pode ser definida como:

O conjunto de enunciados que provém de um mesmo sistema de formação; assim se poderia falar de discurso clínico, discurso econômico, discurso da história natural, discurso psiquiátrico. [...] O discurso está constituído por um número limitado de enunciados para os quais se pode definir um conjunto de condições de existência (FOUCAULT, 2005, p. 124).

Neste sentido, Foucault (1989) entende o discurso como formador da subjetividade, pois liga o sujeito à verdade. Para entender como certos discursos adquirem valor de verdade é necessário abordar o conceito de poder, também em uma perspectiva foucaultiana. Para Foucault (Ibidem), o poder é entendido como um exercício e não uma posse, que apenas se manifesta em ação e em relação. Indivíduos e instituições se relacionam (de maneira desigual) e relações hierárquicas são estabelecidas, de modo que, por meio destas, discursos adquirem (ou não) valor de verdade.

A compreensão de construções discursivas da forma como Foucault $(1989 ; 2005)$ as concebe, está intimamente atrelada à noção de linguagem como constitutiva daquilo que, em um primeiro momento, nomeia. Nessa compreensão, contudo, o ser humano não emerge apenas como produto dos discursos, pois, em ato, (re) produz discursos e, também, resiste a eles, em um jogo permeado por relações de poder. Assim, o indivíduo não é constituído apenas como oprimido e moldado pelos regimes de poder, mas entra em um jogo direto de negociação, podendo produzir fissuras, rachaduras às normas e aos discursos vigentes.

A noção de discurso, da forma como é concebida por Foucault (2005), emerge como ponto de partida para a análise do livro didático. Nessa perspectiva, o livro, enquanto artefato cultural, é produzido e produz discursos de gênero e de sexualidade, constituindo, consequentemente, pedagogias a esse respeito. Para identificar tais discursos, suas condições de existência e, também, de 
resistência, assim como seus efeitos, recorre-se aqui a uma ferramenta metodológica complementar, baseada na perspectiva Queer (LOURO, 2004).

Quando aborda a desconstrução, a perspectiva Queer recorre aos escritos de Derrida para conceber um método com enfoque em uma estratégia descritivo-analítica. Assim, descrever torna-se parte importante do processo analítico: descrever o discurso, suas relações, suas condições de existência, para assim operar uma análise de suas formas, suas produções. Nesse sentido, a perspectiva Queer compreende que a descrição faz parte do processo de análise, uma vez que é operada por um(a) pesquisador(a) constituído(a) de crenças, valores, subjetividades diversas, o que produz efeitos no próprio trabalho descritivo (PARAÍSO, 2014).

A partir da compreensão de que o livro, enquanto artefato cultural, é produzido e produz discursos de e sobre gênero e sexualidade, por meio de relações de poder, a análise de seu conteúdo foi realizada com base no método da desconstrução. A perspectiva Queer, nesse sentido, importa não apenas porque tem na desconstrução sua ferramenta metodológica, mas porque provoca quem se apropria de seu referencial teórico-metodológico a ultrapassar a busca por representações plurais, de modo a enfocar os discursos de/sobre gênero e sexualidade de forma mais complexa, expondo jogos de poder, conflitos e, no limite, relações ambivalentes, tão características da contemporaneidade (LOURO, 2004).

De posse desta abordagem metodológica, a próxima seção é dedicada à apresentação e posterior análise do livro didático selecionado.

\section{Os caminhos de gênero propostos pelo Way To Go}

O livro Way To Go! (WTG), de Claudio Franco e Kátia Tavares, teve sua segunda edição aprovada pelo PNLD, datada de 2016. O livro é distribuído pela Editora Ática e, segundo o Guia do PNLD (BRASIL, 2017), concebe a linguagem a partir da perspec- 
tiva sociointeracional, com base nos estudos bakhtinianos. É composto de uma variedade de gêneros discursivos, e, conforme o guia indica, apresenta temas de relevância social (Ibidem).

O WTG é disposto em oito unidades, cada uma com seis seções: Warming up; Reading; Language in use; Listening and speaking; Writing; Looking ahead (Ibidem). Há, também, a presença de unidades de revisão e a proposta de projetos de natureza interdisciplinar. $\mathrm{O}$ apêndice com Language Reference e algumas regras da língua inglesa, incluindo também atividades adicionais, encerra o livro.

Dentre as suas seções, a presente análise compreendeu o conteúdo das chamadas Units (da 1 a 8), apenas. Ou seja, a apresentação do livro, as Reviews presentes ao final de cada duas Units, os Projetos Interdisciplinares e o apêndice não fizeram parte, porque entende-se que não compreendem o conteúdo mais utilizado do livro, isto é, aquele com o qual discentes certamente terão mais contato, e que portanto precisa mais do que nunca estar comprometido com os tópicos aqui explorados.

$\mathrm{Na}$ presente análise, a discussão sobre gênero e sexualidade foi dividida em dois grandes eixos construídos com base nos tópicos essenciais referenciados pelo PNLD. Primeiramente, foi abordada a representatividade da mulher; após, os lugares de gênero produzidos pelo livro. O debate acerca da violência contra a mulher foi inviabilizado, pois o livro não abarca esta questão, e a abordagem à sexualidade acabou absorvida pela de gênero, não compondo espaço considerável para a criação de um terceiro eixo analítico.

\section{Representatividade da mulher}

Considerando a indicação do guia do PNLD sobre a reapresentação de mulheres de forma não estereotipada, e também de ampliação do leque de possibilidades de representação feminina, esta seção dedicou-se a verificar de que forma as mulheres foram incorporadas no WTG.

Primeiramente, em termos de ilustrações, o livro apresenta pouca variedade. A Unit 1, intitulada "Estudando com Tecnologia" 
(tradução nossa) (FRANCO; TAVARES, 2016, p. 21) compõe em seu texto inicial cinco imagens de pessoas interagindo com tecnologia. Destas, duas são integradas por mulheres e quatro por homens (uma delas apresenta um menino e duas meninas). Aparecem, nas imagens, tecnologias como tablet, players de música, computadores e videogames, mas as meninas interagem apenas com um computador (em um ambiente semelhante ao de uma biblioteca) e com música, enquanto os meninos interagem com todas as tecnologias citadas. De forma semelhante, entre as quatro imagens que compõem a primeira parte da Unit 5, focada em "heroes", é possível localizar apenas uma heroína: Mulher Maravilha. As outras três imagens são de homens, e entre essas há um "herói” da vida real, Ayrton Senna, mas nenhuma mulher. $\mathrm{Na}$ Unit 7, que oferece como tópico de discussão os jogos de videogame, o texto que compõe o Reading apresenta a imagem de um menino, de costas, jogando videogame. O texto discorre sobre o potencial exercício físico praticado por jovens ao jogarem games que exigem a movimentação do corpo, como os de dança e de esportes com motion. Na seção intitulada Language in Use, tem-se acesso apenas a imagens de meninos jogando videogame, a primeira em forma de desenho, na página 131, e a segunda na forma de fotografia, na página 132. Como efeito, em pelo menos três momentos em que imagens são relacionadas à videogame, há apenas homens como protagonistas.

A partir dos elementos aqui descritos, é possível evidenciar que o livro dedica menor espaço em suas ilustrações às mulheres, sobretudo quando o tema da unidade envolve características consideradas, pelo senso comum, próprias do universo masculino. Seja em questões de tecnologia, seja quando o assunto são super-heróis, as mulheres compõem sempre uma minoria não apenas em termos quantitativos, mas também porque, quando compõem as imagens, sua atuação fica restrita a tecnologias e narrativas específicas. As mulheres apenas são maioria na ilustração da Unit 4, com enfoque nas artes e nos sentimentos. As imagens dessa unidade compreendem quatro pinturas famosas. Dessas, a mulher emerge como ob- 
jeto artístico em duas: na famosa Monalisa e em outra pintura, de menor reconhecimento, em que uma mulher chora. Contudo, não é autora de nenhuma, uma vez que todos os artistas contemplados ali são homens. Nessa mesma unidade, na seção intitulada Looking Ahead, a discussão é finalizada referenciando somente pintores homens. Dessa forma, a Unidade inteira dedica às mulheres espaço unicamente enquanto objeto artístico, mas invisibiliza sua capacidade de produzir arte.

Louro (2004) explica que, com frequência, a mulher foi (e ainda é) objeto do olhar nas telas de cinema, ou seja, a mulher é objetificada, porque está ali sobretudo para ser olhada. Tal recorrência é ampliada no livro analisado, de modo a reforçar uma tradição artística que compõe o corpo feminino desde como objeto de desejo, até como objeto de ódio e pavor, sem, contudo, complexificar seu olhar, produzindo arquétipos de feminilidade. No caso das obras de arte da Unit 4, a presença feminina emerge como objetificação sobretudo quando comparada com as ilustrações das demais Units, nas quais, em nenhum momento, as mulheres representaram maioria ou, pelo menos, equivaleram em número aos homens. Ademais, importa lembrar que o outro tema da referida unidade diz respeito aos sentimentos, e em um dos quadros é possível contemplar a imagem de uma mulher aos prantos. Como efeito, a imagem opera como mera ilustração: associa sofrimento à mulher, e não oferece uma imagem que desafie tais expectativas sobre o gênero feminino.

E, de fato, as ilustrações por si só não podem compor sentido sem que se analise também o contexto em que estão imersas. Nesse sentido, retornando à Unit 5, cujo tema é heroísmo, para além do reforço da figura masculina como herói, a referida unidade, sequencialmente, disponibiliza uma série de frases para a(o) discente classificar se, aquilo que está escrito, corresponde ao "herói moderno ou ao herói clássico" (FRANCO \& TAVARES, 2016, p. 90). Todas as frases oferecem apenas a palavra "be", isto é, "ele", para iniciar a reflexão. Ou seja, a/o discente é convidado a construir 
seu raciocínio em inglês partindo do pressuposto de que heróis são sempre "eles", jamais "elas".

Apenas na seção Listening and Speaking há o primeiro momento em que mulheres e homens encontram paridade, pelo menos em termos quantitativos - o que não significa, portanto, equidade. Nessa seção, são apresentadas pessoas reais como "heroínas e heróis", devido aos seus feitos históricos. De um total de quatro, duas são mulheres: Zilda Arns e Indira Gandhi, sendo essa última referida como uma poderosa representante política na Índia (FRANCO \& TAVARES, 2016, p. 99). No entanto, na seção Looking Ahead, que compõe a mesma unidade e é localizada na página 102, são indicados alguns atletas considerados heróis, e nenhum deles, seja nas imagens, seja no texto escrito, são mulheres.

Como efeito, a Unit 5 reservou às mulheres pequeno e singelo espaço. Uma vez que a noção de Heroes remete, no senso comum, a uma qualidade masculina, o WTG poderia ter aproveitado o tópico para desconstruir essa associação histórica e limitadora, contudo, recorreu justamente a ela para compor a referida unidade.

$\mathrm{Na}$ Unit 6, dedicada a invenções e inventores(as), e que tem seu início na página 103 - no Warming Up -, apenas Albert Einstein é citado como referência. No texto que compõe o Reading, são apresentadas invenções e inventores famosos, todos homens, como Frank Epperson e Percy Spencer. A primeira referência a uma mulher inventora emerge apenas na seção Language in Use (página 110): Mrs. Wakefield, à qual é atribuída a invenção, por acidente, de biscoitos de chocolate. Quando comparada com outros inventores que o capítulo apresenta, ela é a única que é nomeada a partir de seu sobrenome de casada e do prefixo "mrs", utilizado na língua inglesa para se referir a mulheres casadas. Ademais, sendo a única mulher a ser citada no capítulo, sua representatividade está resumida ao âmbito da cozinha, às coisas comumente atribuídas às mulheres (e, também, às invenções “por acidente”). Ainda que existam muitas inventoras em diversos ramos de conhecimento, inclusive no ramo da informática, o livro negligencia esta informação de intensa re- 
levância histórica, e acaba por reforçar lugares de gênero na figura da mulher que, enquanto inventora, só o será "por acidente" e no âmbito restrito das atribuições "do lar".

Por último, na seção Looking Ahead, ainda dedicada a invenções, há uma charge com dois cientistas em um laboratório, ambos homens. É importante lembrar que o propósito desta seção, presente em cada unidade, é aprofundar o tema proposto pela Unit em questão ou relacioná-lo com outras questões relevantes, de forma a instigar o debate em sala de aula. No entanto, mais uma vez o livro invisibiliza o debate sobre mulheres cientistas. A Unit 6, dessa for$\mathrm{ma}$, referenciou quinze cientistas: quatorze referências masculinas e uma feminina, apenas.

De modo geral, a Unit 7, dedicada a videogames, não recorreu a expectativas de gênero em sua forma escrita. Contudo, também não problematizou a restrita relação entre videogames e masculinidade; pelo contrário, reafirmou esta relação, invisibilizando a representatividade de mulheres no universo dos videogames, seja por meio das ilustrações, já abordadas, seja por meio do texto, que em nenhum momento cita videogames como um interesse também feminino.

$\mathrm{Na}$ Unit 8, dedicada a discutir literatura, tanto no Warming Up quanto no Reading é abordado apenas um escritor: Langston Hughes, poeta e escritor negro estadunidense. No poema do autor, vê-se ainda uma imagem em preto e branco de um jovem negro, de paletó, que parece envelhecida pelo tempo. Esta unidade, apesar de ter abordado a questão racial por meio das discussões propostas a respeito do trabalho de Hughes, apresentou como referência exclusivamente o trabalho de homens. Às mulheres delegou sobretudo a função de ilustração, através de imagens que visam a informar à/ ao discente sobre o tópico ou exercício a ser trabalhado. Encontramos referência a uma escritora, Judith Rodriguez, somente na seção Looking Ahead - seção que termina a unidade -, que apresenta citações de quatro poetas, sendo, portanto, os outros três, homens. 


\section{Lugares de Gênero}

A seção Language in Use objetiva trabalhar a gramática de forma mais explícita, apresentando regras e situações em que estas se aplicam. Na Unit 1, tem-se um poema para ser interpretado (FRANCO \& TAVARES, 2016, p. 29). O poema, intitulado My sister is always on the phone ${ }^{1}$, de autoria de Bruce Lansky, dedica-se a contar, em versos, a visão de um irmão mais novo sobre sua irmã. Em linhas gerais, o menino explica que sua irmã tem péssimas notas e está a perigo de repetir de ano por ser muito popular e, consequentemente, estar sempre ao telefone. O poema é acompanhado de um desenho, em que se vê uma criança observando a irmã, deitada na cama, sorrindo e ao telefone, ao lado de livros fechados. Vê-se, também, o cartaz de um homem musculoso, de sunga, colado na parede. Em um sentido parecido, A Unit 2, dedicada à discussão sobre o meio ambiente, apresenta um desenho composto de diversos pequenos textos sobre cuidados ao meio ambiente. $\mathrm{Na}$ seção Language in Use, na página 43, o livro produz lugares de gênero ao dispor de duas imagens: a primeira, em que uma mulher encontra-se em frente à geladeira ou seja, na cozinha -, e a segunda, em que um homem está ao ar livre, praticando jardinagem. No mesmo sentido, na página 44, vê-se uma outra mulher no supermercado, fazendo compras, enquanto um homem está sentado confortavelmente num sofá, assistindo à televisão. Tais imagens, contudo, não são apresentadas em um contexto de discussão dessas expectativas de gênero, mas sim sobre os cuidados que podemos ter com o meio ambiente.

Ambas as Units reduzem o lugar da mulher e sua sexualidade. O efeito da heteronormatividade (LOURO, 1997) é manifesto por meio da redução dos interesses femininos em meninos, em atividades consideradas superficiais (como estar ao telefone ao invés de estudar) e reduzidas ao âmbito privado, às tarefas domésticas, enquanto o homem permanece relacionado ao ar livre e ao lazer.

A Unit 4, por sua vez, com a proposta de discutir artes e emoções, oferece a pintura Woman Crying (1984), que consiste em uma

\footnotetext{
${ }^{1}$ Em português, "minha irmã está sempre ao telefone" (tradução nossa).
} 
mulher a chorar. Relacionada à pintura, propõe a seguinte pergunta: "Na sua opinião, quem chora com mais frequência: homens ou mulheres? Por quê?" (FRANCO \& TAVARES, 2016, p. 71) (tradução nossa). Apesar de ser uma pergunta que instiga ao debate, não há nesta unidade nenhuma problematização a respeito da compreensão do senso comum, que diz que as mulheres choram mais que os homens. Pelo contrário, o livro reafirma o senso comum, pois, ao indagar à(ao) discente o que espera encontrar no texto que compõe a seção seguinte, sugere que será discutido "por que mulheres choram mais" (tradução nossa) (Ibidem, p.71). Ou seja, o livro já indica seu posicionamento em relação a essa questão, ao partir do pressuposto de que mulheres choram mais e que o texto explicará o porquê. Ademais, encontra-se a palavra "hormônios" (tradução nossa) (Ibidem, p. 71) dentre as apresentadas como esperadas de serem localizadas no texto. Como efeito, o livro sugere à(ao) docente como tratar esses assuntos, e, se ele/ela não tem uma visão crítica sobre as expectativas e lugares de gênero, diversos discursos naturalizados como verdade poderão ser reafirmados, e não desconstruídos.

De maneira semelhante, o texto desta mesma unidade oferece uma matéria da revista Natural Health, intitulada Is crying good for you? (chorar é bom para você?) (FRANCO \& TAVARES, 2016, p. 72). Logo no primeiro parágrafo, lê-se:

Por que choramos Humanos costumam chorar para solicitar ajuda e serem confortados, e às vezes para afastar atos de agressão de outras pessoas (o choro feminino pode impedir homens de serem agressivos). O choro tem essa função em bebês indefesos, e temos poucas razões para acreditar que isso muda quando as pessoas crescem (ACOSTA apud FRANCO \& TAVARES, 2016, p. 72) (tradução nossa).

O excerto destacado aciona diversos discursos do senso comum sobre lugares de gênero. Primeiramente, dispõe (apenas) um lugar para as mulheres e (apenas) um lugar para os homens: mulheres choram, homens são agressivos. Consequentemente, incumbe às mulheres (por meio de suas lágrimas) a função de im- 
pedir a agressividade do homem. A seguir, a autora encontra, na prática de "bebês indefesos", a mesma função do choro associada às mulheres, e dessa forma aproxima feminilidade e infantilidade 2 . Apesar de finalizar o excerto dizendo que esta função pouco muda na idade adulta, o que pode sugerir que quaisquer bebês podem, quando mais velhos, continuar recorrendo ao choro, em nenhuma parte desse excerto ou do artigo completo a autora relaciona explicitamente o pranto aos homens, ou os classifica como passíveis de sentirem-se indefesos. Há, ainda, outro momento em que a autora pensa especificamente a relação das lágrimas com os gêneros:

Por que mulheres choram mais Primeiramente, o hormônio masculino testosterona tende a inibir o choro, enquanto o hormônio feminino prolactina pode diminuir o limiar emocional. Ademais, mulheres podem estar expostas a situações mais emocionantes, como o ato de ser cuidadora, e costumam ser mais empáticas. Por último, homens geralmente são convocados a controlarem suas lágrimas (ACOSTA apud FRANCO \& TAVARES, 2016, p. 72) (tradução nossa).

Como o excerto permite concluir, Acosta assume como um dado fatídico que mulheres choram mais, sem apresentar qualquer estudo ou referência científica para dar base a essa afirmação. Para sustentar sua lógica, recorre a indícios biológicos e culturais, mas de forma superficial e isolada. $\mathrm{Na}$ descrição dos motivos, elenca como primeiro (e, dessa forma, mais importante) aquele que diz respeito à biologia dos corpos nomeados femininos e masculinos. Faz, na verdade, mais do que isso: nomeia hormônios como femininos e masculinos, ignorando o fato de que mulheres também possuem testosterona e homens prolactina em seus corpos, por exemplo. Neste sentido, o texto se apropria inclusive de saberes difundidos em livros próprios da área de biologia, como evidenciado em pesquisa de Silva e Coutinho (2016).

2 Sobre a relação histórica entre feminilidade e infância, sugere-se o trabalho de Jane Felipe (2006). 
De fato, como explica Jeffrey Weeks (2000), a sexologia resumiu a sexualidade e o gênero ao âmbito da natureza, entendido como instinto, energia incontrolável, um efeito de uma preocupação pós-darwiniana. Ainda que hoje sejam outras as áreas que detêm a expertise em relação à sexualidade e ao gênero, que não a sexologia, essas áreas (uma delas a biologia) receberam tal herança histórica, que persiste ainda hoje, e que reside na compreensão da constituição biológica como explicação natural para todas as coisas. Neste sentido, "natural" diz respeito sobretudo à ideia de que comportamentos e manifestações sexuais e de gênero encontram na biologia motivo para sua existência, o que exime a cultura e o contexto histórico desse processo.

No entanto, como contesta Butler (2004, p.155): “'Admitir' a inegabilidade do 'sexo' ou sua 'materialidade' significa sempre admitir alguma versão de 'sexo', alguma formação de 'materialidade'. Não seria o discurso no - e através do — qual essa admissão ocorre (...) formativo do exato fenômeno que ele admite?". Com sua colocação, a autora questiona a noção de que há um conhecimento puramente natural e biológico sobre os corpos, as sexualidades e os gêneros. Isto porque, ao assumir a língua como lócus de construção discursiva sobre esses temas, é difícil admitir que reste, nesse processo, algum conhecimento que não seja produzido pela própria função discursiva. Ou seja, a noção de referente é deslocada do lugar de natural, porque esse lugar deixa de ser natural na medida em que a língua se apropria dele. Nesse sentido, a compreensão biológica, à qual a jornalista - autora do artigo reproduzido no livro - recorre para justificar a tendência de mulheres a serem mais emotivas, desconsidera que tais hormônios e suas funções estão atrelados e imersos em uma realidade social e histórica muito complexa.

Entretanto, ainda nesta unidade, a subseção Reading for Critical Thinking oferece algumas questões que possibilitam debater sobre os discursos do senso comum. Em uma das perguntas, é indagado se mulheres e homens expressam seus sentimentos da mesma forma, se homens precisam controlar seus sentimentos. Em outra 
questão, é apresentada uma série de quadros que retratam mulheres chorando, e se questiona se a literatura e as artes, em geral, representam diferentemente os sentimentos de homens e mulheres. De fato, tais questionamentos instigam ao debate, mas não necessariamente direcionam para uma problematização do senso comum, na medida em que todas essas questões podem ser respondidas por ele - pelo senso comum - e, também, pelo texto problemático apresentado na unidade e aqui analisado.

\section{Considerações finais}

O objetivo deste artigo foi analisar um dos livros aprovados pelo PNLD de 2017 para o ensino da língua inglesa, de forma a problematizar os discursos que dele emergiram a respeito das relações de gênero.

Para tanto, foi preciso abordar os próprios documentos que regem a composição do currículo escolar, de modo entender como o livro se aproximou ou se distanciou das recomendações daqueles. Foi necessário, também, discorrer sobre a metodologia de análise selecionada, que compreendeu a análise de discurso foucaultiana e a perspectiva Queer.

A organização das discussões de gênero, possibilitadas pelo WTG, deu-se a partir de dois grandes eixos que o guia do PNLD indicou como necessários aos livros didáticos: a representatividade feminina e a desnaturalização dos lugares de gênero normativos. O primeiro possibilitou visualizar que a mulher pouco compôs o arsenal de ilustrações e de discursos textuais das unidades do WTG e, quando o fez, funcionou sobretudo como objeto de contemplamento: associada aos sentimentos ou com uma função meramente ilustrativa. Assim, permaneceu invisibilizada, principalmente em discussões tidas pela norma como próprias do universo masculino.

Em relação ao segundo tópico de discussão, com enfoque sobre as relações e lugares de gênero, novamente por meio de imagens o WTG limitou o espaço de atuação feminino. Às mulheres, o WTG reservou o âmbito privado e os afazeres domésticos. Além 
disso, associou-as sobretudo às emoções, dedicando um texto inteiro (o único sobre mulheres, importante destacar) a reforçar um suposto descontrole emocional feminino.

Neste sentido, o livro Way to Go! não cumpriu com as expectativas do PNLD, no que diz respeito à violência contra a mulher, discriminações de gênero e de sexualidade e, sobretudo, em relação à representatividade feminina (BRASIL, 2017). Pelo contrário, (re) produziu expectativas de gênero e de sexualidade e possibilitou ínfimos momentos de discussão sobre alguns desses assuntos.

Como efeito, o presente exercício analítico se fez importante na medida em que reafirmou a importância de que a questão de gênero e de sexualidade adentre, efetivamente, os livros didáticos. Mais do que isso, demonstrou que o referido livro sequer cumpre com exigências mínimas nesse sentido, que dirá propor uma abordagem crítica que, mais do que contemple pluralidades, problematize os discursos do senso comum, de modo a tensionar concepções limitadas e hierarquizantes das relações de/entre gêneros e sexualidades.

\section{Referências}

Brasil. Secretaria de Educação Fundamental. Parâmetros curriculares nacionais: introdução aos parâmetros curriculares nacionais / Secretaria de Educação Fundamental. - Brasília : MEC/SEF, 1997. 126p.

Brasil. Ministério da Educação. Secretaria de Educação Básica. Secretaria de Educação Continuada, Alfabetização, Diversidade e Inclusão. Conselho Nacional da Educação. Diretrizes Curriculares Nacionais Gerais da Educação Básica/ Ministério da Educação. Secretária de Educação Básica. Diretoria de Currículos e Educação Integral. - Brasília: MEC, SEB, DICEI, 2013.

Brasil. Ministério da Educação. PNLD 2018: inglês - guia de livros didáticos - ensino médio/ Ministério da Educação - Secretária de Educação Básica - SEB - Fundo Nacional de Desenvolvimento da Educação. Brasília, DF: Ministério da Educação, Secretária de Educação Básica, 2017. 87 p.

BUTLER, Judith. Corpos que pesam: sobre os limites discursivos do "sexo". In: LOURO, Guacira Lopes. Um corpo estranho: ensaios sobre sexualidade e teoria queer. Belo Horizonte: Autêntica, 2004. 
FOUCAULT, Michel. A arqueologia do saber. Rio de Janeiro: Forense Universitária, 2005, 7 ed.

FOUCAULT, M. História da Sexualidade I: a vontade de saber. Rio de Janeiro: Graal, 1989.

FRANCO, Claudio de Paiva. Way To Go!: língua estrangeira moderna : inglês: ensino médio. 2 ed.. São Paulo: Ática, 2016.

LAQUEUR, Thomas. Inventando o sexo: corpo e gênero dos gregos a Freud. Rio de Janeiro: Relume, Dumará, 2001.

LOURO, Guacira Lopes. Um corpo estranho: ensaios sobre sexualidade e teoria queer. Belo Horizonte: Autêntica, 2004.

LOURO, Guacira Lopes. O corpo educado: pedagogias da sexualidade. 2. ed. Belo Horizonte, MG: Autêntica, 2000.

LOURO, Guacira Lopes. Gênero, sexualidade e educação - uma perspectiva pós- estruturalista. Petrópolis: Vozes, 1997, 6 ed.

OLIVEIRA, Rosana Medeiros de. Descolonizar os Livros Didáticos: raça, gênero e colonialidade nos livros de educação do campo. In: Revista Brasileira de Educação. Rio de Janeiro, v. 22, n. 68, p. 11-33, jan.-mar. 2017.

SILVA, Fábio Augusto Rodrigues; COUTINHO, Francisco Ângelo. Realidades Colaterais e a Produção da Ignorância em Livros Didáticos de Biologia: um estudo sobre hormônios e a questão de gênero. In: Investigações em Ensino de Ciências. V.2(3), dez. 2016, p. 176-194.

WEEKS Jeffrey. O corpo e a sexualidade. In: LOURO, Guacira Lopes. O corpo educado: pedagogias da sexualidade. 2. ed. Belo Horizonte, MG: Autêntica, 2000.

Submetido em: 20-11-2020

Aceito em: 27-7-2021 